\title{
Gentrification and Residential Mobility in Philadelphia
}

\author{
Lei Ding*, \\ Federal Reserve Bank of Philadelphia \\ Jackelyn Hwang, and \\ Princeton University \\ Eileen Divringi \\ Federal Reserve Bank of Philadelphia
}

\begin{abstract}
Gentrification has provoked considerable controversy surrounding its effects on residential displacement. Using a unique individual-level, longitudinal data set, this study examines mobility rates and residential destinations of residents in gentrifying neighborhoods during the recent housing boom and bust in Philadelphia for various strata of residents and different types of gentrification. We find that vulnerable residents, those with low credit scores and without mortgages, are generally no more likely to move from gentrifying neighborhoods compared with their counterparts in nongentrifying neighborhoods. When they do move, however, they are more likely to move to lower-income neighborhoods. Residents in gentrifying neighborhoods at the aggregate level have slightly higher mobility rates, but these rates are largely driven by more advantaged residents. These findings shed new light on the heterogeneity in mobility patterns across residents in gentrifying neighborhoods and suggest that researchers should focus more attention on the quality of residential moves and nonmoves for less advantaged residents, rather than mobility rates alone.
\end{abstract}

\section{Keywords}

gentrification; residential mobility; neighborhood change; displacement; Philadelphia

\section{Introduction}

Neighborhoods in many central cities have started to rebound due to recent demographic and economic shifts and renewed interest in urban living. Gentrification describes the socioeconomic upgrading of a previously, low-income central city neighborhood, characterized by the influx of residents of a higher socioeconomic status relative to incumbent residents and rising home values and rents. ${ }^{1}$ The demographic changes that occur

\footnotetext{
*Corresponding author. Please direct correspondence to Lei Ding, The Federal Reserve Bank of Philadelphia, Ten Independence Mall, Philadelphia, PA 19106; lei.ding@phil.frb.org.

Publisher's Disclaimer: This is a PDF file of an unedited manuscript that has been accepted for publication. As a service to our customers we are providing this early version of the manuscript. The manuscript will undergo copyediting, typesetting, and review of the resulting proof before it is published in its final citable form. Please note that during the production process errors may be discovered which could affect the content, and all legal disclaimers that apply to the journal pertain.
} 
in gentrifying neighborhoods imply the residential displacement of long-term, often older or low-income, residents by younger and high-income residents. The empirical evidence on the relationship between gentrification and residential displacement, however, is far from conclusive.

Early studies examining displacement and gentrification typically lack individual-level, longitudinal data or an appropriate comparison group of neighborhoods to assess mobility rates in the absence of gentrification (see review in Freeman, 2005). A handful of recent studies have overcome these issues and generally do not find evidence that less-educated, renting, minority, and lower-income households are more likely to move from gentrifying neighborhoods relative to similar residents in nongentrifying neighborhoods (Ellen and O' Regan, 2011; Freeman, 2005; Freeman and Braconi, 2004; McKinnish, Walsh, and White, 2010; Vigdor, 2002). These studies of gentrification, however, have various limitations often due to data constraints that require defining neighborhoods as very large spatial aggregations, defining gentrification too broadly, or examining mobility over relatively long intervals (usually 10-year intervals).

We overcome these limitations by drawing from a unique individual-level, longitudinal data set - the Federal Reserve Bank of New York Consumer Credit Panel/Equifax data (hereafter noted as CCP). The data contain quarterly updated information on more than 50,000 adult residents in Philadelphia from 2002-2014, which allows us to study residential mobility across various strata of residents from similar neighborhoods over short time intervals. Unlike previous studies, we are also able to examine the types of neighborhoods to which residents move. Whether residents that are unable to stay in gentrifying neighborhoods move to poorer or wealthier neighborhoods is an important dimension of residential displacement for which there is limited evidence. Furthermore, despite the fact that gentrification is an evolving process that occurs at different rates in various neighborhoods (Hwang and Sampson, 2014), few studies have considered how mobility patterns may vary by a neighborhood's pace or stage of gentrification. We are able to analyze this with the large number of individuals tracked in the study. Lastly, previous studies have not analyzed the period following the year 2000, when gentrification became increasingly rapid and widespread relative to the past, particularly during the housing boom in the early 2000s, and would, therefore, be more likely to displace residents (Newman and Wyly, 2006).

The following questions motivate our study: 1) Are residents in gentrifying neighborhoods more likely to move than residents in low-income, nongentrifying neighborhoods? 2) Are residents who move from gentrifying neighborhoods more likely to move to lower-income neighborhoods? 3) Do these outcomes differ for residents who are particularly vulnerable to displacement in gentrifying neighborhoods? 4) Do these outcomes differ by the stage or pace of gentrification of a neighborhood? 5) Do these outcomes differ by when they took place in the context of the housing boom and bust?

${ }^{1}$ Following most studies of gentrification, we consider gentrification a phenomenon that occurs at the neighborhood level within central urban areas rather than across entire cities or in rural or suburban towns. 
Our findings indicate that gentrification affects residential mobility patterns of different groups of residents in distinct and important ways. On average, residents in gentrifying neighborhoods have slightly higher mobility rates than residents in low-income neighborhoods that did not gentrify, and at the aggregate level movers out of gentrifying neighborhoods are no more likely to move to lower-income neighborhoods compared with those from nongentrifying, low-income neighborhoods. These mobility patterns, however, are largely driven by residents with higher credit scores and occur primarily in rapidly gentrifying neighborhoods or neighborhoods that have been gentrifying for a long time. Residents with low credit scores and without mortgages are generally no more likely to exit these types of gentrifying neighborhoods compared with similar residents in nongentrifying neighborhoods. When they move from these neighborhoods, however, they are much more likely to move to lower-income neighborhoods, especially in the years after the Great Recession. While the findings are consistent with recent studies on gentrification and residential mobility rates, they further demonstrate distinct and unequal mobility patterns out of gentrifying neighborhoods that vary systematically by residents' credit scores and mortgage status, as well as by the stage or pace of gentrification of the neighborhood and by different economic cycles. Further, empirical results on the residential destinations of movers help fill a gap in the literature and demonstrate the importance of the investigation of the quality of residential moves, in addition to the overall mobility rates, for less advantaged residents.

\section{Literature Review and Background}

\subsection{Gentrification and Residential Displacement}

Residential displacement has been a central point of contention surrounding gentrification (e.g., Ahlfeldt, 2011; Ellen and O'Regan, 2011; Freeman, 2005). As neighborhoods gentrify and new residents of a higher socioeconomic status relative to incumbent residents move in and housing values and rents rise, housing and living costs may lead less advantaged incumbent residents to move out of the neighborhood against their will. Most existing studies on the population composition of gentrifying neighborhoods find that demographic changes take place at the aggregate neighborhood level. This implies that long-term, less advantaged residents are indeed moving out of the neighborhood. Further, anecdotal accounts show that residents move out of gentrifying neighborhoods by choice or through eviction as landlords increase rents, property taxes increase as local home values and rents rise, or because developers offer existing residents relatively large cash sums and then renovate the properties for larger profits (Newman and Wyly, 2006; Freeman, 2005). Few studies, however, have examined the moves of individual residents in gentrifying neighborhoods to support this.

The first set of quantitative studies to examine the relationship between gentrification and residential displacement lack the necessary data to warrant conclusive evidence on the issue. These studies observed differences in the characteristics of residents moving into and out of gentrifying neighborhoods (e.g., Spain, Reid, and Long, 1980), conducted surveys asking residents why they had moved but often without information on the previous residential 
location (e.g., Grier and Grier, 1978), or focused on mobility rates as neighborhoods gentrified without comparing nongentrifying neighborhoods (e.g., Schill and Nathan, 1983).

Using richer data, Vigdor (2002), Freeman and Braconi (2004), and Newman and Wyly (2006) examined individual moves in Boston from 1974-1998, New York City from 19911999, and New York City from 1991-2002, respectively. The studies find that lower-income and less-educated households in gentrifying neighborhoods were no more likely to move than similar households in all other neighborhoods. Newman and Wyly (2006) find some evidence of displacement among particular households (foreign-born, poor, elderly, public housing residents, and female-headed households) and find that they tend to move to the outer boroughs of New York City, but they find that many poor renters also stay in gentrifying neighborhoods.

Due to limited sample sizes, a major limitation of the data used in these studies due to limited sample sizes is that they defined neighborhoods as large spatial aggregations comprising over 100,000 residents, which is substantially larger than how neighborhoods are generally operationalized in neighborhood studies and likely attenuated their results (Ellen and O'Regan, 2011; Freeman, 2005). Moreover, these studies compared mobility patterns in gentrifying neighborhoods with all other neighborhoods, rather than an arguably more appropriate control group of low-income neighborhoods that did not gentrify (Freeman, 2005). Lastly, these early studies relied on limited survey responses to questions that asked about reasons for moves, but retrospective responses may not accurately capture residential moves resulting from gentrification (Freeman, 2005).

A handful of studies overcome these issues by using data that enable them to operationalize neighborhoods as census tracts, which have an average of 4,000 residents, while using more comparable neighborhoods and focusing on mobility rates rather than survey responses. Freeman (2005) examines mobility among a national sample of individuals during the 1980s and 1990s and does not find strong evidence that lower-income households are more likely to move out of gentrifying neighborhoods relative to similar households in nongentrifying neighborhoods. The gentrification captured in this period, however, was relatively slow and predates its intensification that took place in the late 1990s and into the 2000s (Ellen and O'Regan, 2011). In addition, due to sample size limitations, the study uses a liberal definition of gentrification that considers a large number of tracts to be gentrifying, and these tracts experienced an average decrease in median household incomes (McKinnish et al., 2010). ${ }^{2}$

McKinnish et al. (2010) use confidential census data to examine mobility during the 1990s across large metropolitan areas and find no evidence that low-educated or minority householders are more likely to move out of neighborhoods that experienced income gains. Nonetheless, they do find that blacks with lower education levels are more likely to move from income-gaining census tracts that are less than 50\% black. However, the data used in this study are limited to decennial observations in 1990 and 2000 and do not follow the same

${ }^{2}$ Freeman (2005) considered a census tract to be gentrifying if it was located in a central city, had both a median income and share of housing built in the last 20 years below the metropolitan area's 40th percentile at the beginning of the census period, and both an above median growth in educational attainment and an increase in real housing prices over the decennial period. 
residents over time. Ellen and O'Regan (2011) improve upon these data limitations using the confidential biennial American Housing Survey from 1991-1999, which observes the same housing units over time. Thus, they are able to observe residential turnover in 2-year intervals instead of 10-year intervals, arguably a more appropriate time frame for examining the mobility of renters - who may be more likely to be displaced because they have less control over their housing situation. Examining low-income census tracts across metropolitan areas, they also do not find evidence of greater exit rates from gentrifying neighborhoods for minorities, poor residents, or renters compared with similar residents in neighborhoods that did not gentrify. While informative for examining mobility, the survey does not provide information on the residential destinations of movers from gentrifying neighborhoods. Lastly, a recent study by Freeman, Cassola, and Cai (2016) uses longitudinal data in England and Wales and also finds little evidence of displacement. ${ }^{3}$

Overall, existing studies generally do not find evidence of elevated rates of mobility among less advantaged residents compared with similar residents in low-income neighborhoods that do not gentrify. The findings suggest that residential moves from gentrifying neighborhoods reflect normal rates of housing turnover among less advantaged residents and that the neighborhood-level demographic changes are largely due to the in-migration of high socioeconomic status residents (Ellen and O'Regan, 2011; Freeman, 2005; McKinnish, et al., 2010). These studies may not detect higher mobility rates because gentrification can take place through infill development or in areas with high vacancy rates, and incumbent residents may be willing to pay the increased costs that come with gentrification if they are able, which may mitigate rates of displacement (Freeman, 2005). Moreover, less advantaged residents may have relatively higher mobility rates due to financial instability and evictions, regardless of whether they are living in gentrifying or nongentrifying neighborhoods (Newman and Wyly, 2006).

These studies, however, also face various data constraints that limit a conclusive assessment of how gentrification affects residential mobility. In particular, these studies define neighborhoods and gentrification rather broadly due to limited sample sizes within geographic areas or examine lengthy time intervals due to data constraints. The large sample of individuals and quarterly observations in the CCP allow us to overcome these issues. In addition, we focus exclusively on a single city to more reliably identify gentrifying neighborhoods and consider variation in the stage and pace of gentrification for assessing displacement. For example, some researchers have argued that displacement may be more likely during the early stages of gentrification, as less advantaged residents without the means to stay are pushed out earlier (Newman and Wyly, 2006).

Our data also permit us to examine where movers from gentrifying neighborhoods relocate. While less advantaged households may not move out of gentrifying neighborhoods at higher rates, Newman and Wyly (2006) argue that gentrification prices out less advantaged residents from areas that they could have afforded originally, limiting affordable housing

\footnotetext{
${ }^{3}$ While our study focuses on residential displacement, other studies also find evidence of political and cultural displacement alienating less advantaged residents in gentrifying neighborhoods, as well as broader economic consequences of gentrification (e.g., Hyra, 2014; Lester and Hartley, 2014).
} 
opportunities and leading lower-income residents to search for housing in more

disadvantaged neighborhoods. This study contributes to the literature by examining where residents move when they leave gentrifying neighborhoods in addition to examining the mobility rates of residents in gentrifying neighborhoods and how mobility patterns vary across different subpopulations, various stages or paces of gentrification, and economic cycles.

\subsection{Gentrification in Philadelphia}

Our study examines residential mobility in Philadelphia from 2002-2014. Like many cities across the country, gentrification has expanded and accelerated in pace in many Philadelphia neighborhoods in recent decades compared with the decades preceding the housing boom in the early 2000s. Nonetheless, the housing market in Philadelphia differs from other areas in important ways that may affect the pace of gentrification and its consequences on residential displacement. Philadelphia has several characteristics contributing to the accelerated pace of gentrification in recent years. With a vibrant downtown and several strong anchor institutions (e.g., University of Pennsylvania and Temple University), Philadelphia has a relatively stable local economy and housing market. Further, its Real Estate Tax Abatement programs, which exempt property owners from certain property taxes for a 10-year period for all eligible new construction or substantial property rehabilitation, offer a generous incentive for new development that helps mitigate pressure on neighborhoods' housing supply. As of March 2013, over 15,000 properties in Philadelphia were abated (Gillen, 2013). In addition, the city of Philadelphia saw a significantly lower foreclosure rate than many other large cities during the most recent housing crisis, though the city experienced housing price and construction declines from 2008-2010 and a slowed recovery from the housing crisis (Pew Charitable Trusts, 2011).

Philadelphia also has several distinct features that may lower the likelihood of residential displacement. First, Philadelphia has a relatively high number of vacant lots and properties available for development and rehabilitation. In 2006, Philadelphia's rental vacancy rate was $12.5 \%$, whereas the average for the 10 other largest U.S. cities was $8.3 \%$ (Capperis, Ellen, and Karfunkel, 2015). Second, Philadelphia has a historically high homeownership rate (63\% in 2006) relative to other major cities (the 10 other largest cities had an average homeownership rate of $47 \%$ ), though this has decreased substantially in recent years (56\% in 2013) (Capperis et al., 2015). Third, Philadelphia had not assessed its properties, particularly older ones, for decades until its launch of a new program (the Actual Value Initiative) in 2014 to simultaneously assess properties based on their actual market values. As a result, long-term homeowners were not subject to property tax increases that often come with increasing property values during our period of analysis (Pew Charitable Trusts, 2012). ${ }^{4}$

Altogether, pressures of displacement may be lower, particularly for homeowners, in Philadelphia compared with tighter housing markets, such as the handful of "superstar" cities experiencing high levels of gentrification like New York City and San Francisco

${ }^{4}$ In 2014, the city implemented a property tax relief program, which prohibits property tax increases for 10 years for low-income homeowners who have lived in their properties for more than 10 years. Any effects from this program would only be evident in the last cohort of analysis. 
(Gyourko, Mayer, and Sinai, 2013). Although Philadelphia is not necessarily generalizable to the whole nation or to cities that have significantly different market conditions, it may better reflect processes occurring in many other major U.S. cities experiencing gentrification that are not "superstar" cities, such as rustbelt cities with similar histories of urban decline and resurgence like Chicago.

While a national-level analysis can shed light on general patterns, measuring gentrification, particularly by applying uniform criteria to capture socioeconomic ascent in neighborhoods across cities, often does not necessarily identify areas associated with gentrification or undergoing similar types of change (Owens, 2012; Barton, 2016). Because we have a large enough sample size to examine residential mobility patterns for various subpopulations and across various types of neighborhoods within a single city, we therefore focus on a single city in this study. Considering the factors associated with a single urban context and various stages of gentrification helps us better understand why we see particular patterns.

\section{Data}

\subsection{CCP Data}

This study relies on the CCP data, which consist of an anonymized 5\% random sample of U.S. consumers in a major credit bureau's total population of eligible individuals, as well as consumers in each sampled individual's household. This sample is constructed by selecting consumers with at least one public record or one credit account currently reported and with one of five numbers in the last two digits of their Social Security numbers (SSNs) (see details in Lee and van der Klaauw, 2010). ${ }^{5}$ The CCP data report the credit characteristics for sample members quarterly beginning in 1999 . Because few studies of residential mobility have used the CCP data (except Molloy and Shan, 2013; Wardrip and Hunt, 2014), we carefully evaluated the representativeness of the CCP data by comparing it to the American Community Survey (ACS) sample in Philadelphia, which we describe in more detail below.

The CCP data have many advantages for studying residential mobility. First, because the CCP data include census geography identifiers based on 2000 census boundaries associated with each consumer's credit file, we are able to identify whether an individual has moved across neighborhoods and to track the origin and destination neighborhood of a mover. A "mover" is defined as an individual who lives in a census tract different from where he or she lived one year ago in this study. Second, the age distribution and population estimates of the CCP sample are similar to those based on the ACS sample in Philadelphia, especially for individuals 25 years of age or older. ${ }^{6}$ Figure 1 displays the population comparisons between the CCP and ACS samples in Philadelphia. Furthermore, the CCP data also provide extensive information on consumer credit use and credit performance, such as an individual's Equifax risk score, which is a widely used credit score and provides a summary measure of

\footnotetext{
${ }^{5}$ The CCP data do not include actual SSNs. Equifax uses SSNs to assemble the data set, but the actual SSNs are not shared with researchers. In addition, the data set does not include any names, actual addresses, demographics (other than age), or other codes that could identify specific consumers or creditors.

${ }^{6}$ The CCP panel has a significantly lower proportion of individuals that are 18-24 years old and a slightly higher proportion of older individuals (65+) compared with the ACS estimates. Although 18-24 year olds are slightly underrepresented in the CCP data, we keep them in the main analysis presented since Millennials may play an important role in the gentrification process. We conduct additional analysis to check the robustness of the results.
} 
an individual's financial health. The risk score ranges from 280 to 850 and is intended to serve as a proxy for the probability that an individual will repay his or her debts without defaulting. Like other credit scores, a high risk score indicates a lower default risk for an individual, while a low risk score indicates a greater likelihood of default. If no score is listed for a consumer, this suggests a thin file (containing very few accounts or the credit is new), such that too little information is provided for estimating a score. Risk scores are useful indicators of socioeconomic status when it comes to the housing market, where landlords screen applicants for rentals with credit history checks and borrowers' access to and pricing of home mortgage products are sensitive to credit scores. Further, risk scores can reflect financial challenges that may be associated with residential displacement. The CCP data, however, contain limited information on household demographic characteristics other than age.

There are a few more caveats of the CCP data worth mentioning. First, the CCP data only sample individuals with a credit history and a SSN, so individuals who have never applied for or qualified for a loan are not included. The Consumer Financial Protection Bureau reports that 26 million Americans (one in 10 adults) do not have any credit history with a nationwide consumer reporting agency as of 2015 (Brevoort, Grimm, and Kambara, 2016). However, the CCP data do include individuals with thin files, as well as individuals whose credit file only consists of a collection or public record item (such as bankruptcy) or only contains authorized user accounts or closed accounts. Thus, the results on residential mobility may not represent the behavior of individuals without credit records or SSNs, such as populations who do not use credit at all or young individuals who have no credit history. ${ }^{7}$ Thus, the CCP panel comprises a sample of relatively financially independent adult individuals.

Second, the mobility rates calculated using the CCP data are slightly lower than those in the ACS data. This is likely due to at least two possible reasons: 1) we do not count those who moved within a census tract; and 2) addresses on credit reports for young adults, such as college students, may be their parents' home addresses, resulting in an underestimate of their actual mobility rates. However, the intercounty mobility rates, especially the interstate mobility rates, are quite similar to those reported in the ACS, which improves our confidence in our methodology to identify interneighborhood moves.

Finally, the sample design of the CCP panel prevents us from tracking mobility for a very small share of newly added/dropped consumers to the panel. The CCP data try to constitute a nationally representative random sample of individual consumers in any given quarter by using a sampling approach that generates the same entry and exit behavior as present in the population. This is done by adding new individuals who develop a credit history or

\footnotetext{
${ }^{7}$ We compared the distribution of low-score residents (with no scores or with scores less than 580 in the CCP) and the share of residents with less than a college degree or below poverty and the share of minorities from ACS data in gentrifying and nongentrifying neighborhoods. We find that while the overall share of low-score residents is lower than the share of non-college-educated or minority residents and higher than the share of residents below poverty, the differences are generally similar between gentrifying and nongentrifying neighborhoods for the education and poverty indicators. However, there are relatively more low-score residents in gentrifying than nongentrifying neighborhoods compared with nonwhite residents. This is not surprising because many gentrifying neighborhoods were initially low-income, predominantly white neighborhoods.
} 
immigrate to the U.S. over time and by dropping consumers when they die, emigrate, or "age off," having a prolonged period of inactivity and no new items of public record. ${ }^{8}$

We make the following decisions to construct the study sample for our empirical analysis based on our evaluation of the data. Our study period begins in June 2002 and ends in June 2014. The geographic information in the data was reported to be less precise prior to 2002 (Wardrip and Hunt, 2014). Thus, we exclude the data in earlier years to avoid introducing selection issues that would compromise the analysis. We also exclude the 2005 cohort because the mobility rate in 2005 was abnormally high, which is likely due to the change in the geocoding system used by the data vendor in that year. In addition, we drop individuals who were recorded as "deceased" in the study sample, observations for which the first and last observation were less than 12 months apart, ${ }^{9}$ and a few very young individuals (17 years old or younger) and very old individuals (older than 84 years). Finally, we use annual mobility rates as the main outcome in our analysis to mitigate the potential bias introduced by the attribution and adjustment of the study sample. Thus, we structure our analytic dataset to consist of separate cohorts that we observe over each year.

\subsection{Gentrification Measures}

Empirical studies of gentrification have little agreement on its definition and, relatedly, its operationalization. For our study, we conceptualize gentrification as the socioeconomic upgrading of a previously low-income, central city neighborhood, characterized by the influx of higher socioeconomic status residents and an increase in housing prices. This definition is consistent with most characterizations of gentrification in the existing literature. Although some scholars define gentrification by racial turnover or displacement, several scholarly accounts of gentrification find that gentrification does not necessarily follow these patterns (e.g., Freeman, 2005; Pattillo, 2007). Others operationalize gentrification exclusively by income changes (e.g., Ellen and O'Regan, 2011; McKinnish et al., 2010), but income shifts do not necessarily capture gentrifying neighborhoods, particularly when gentrification is driven by residents with relatively lower incomes, like students, recent graduates, or artists, or when incumbents experience income gains (Owens 2012). By relying on a single city in this study, we are also able to draw upon local knowledge and resources to validate our measures.

We construct measures of gentrification using decennial U.S. Census data from 1980, 1990, and 2000 and ACS 5-year estimates for 2009-2013 for Philadelphia census tracts. ${ }^{10}$ These data are harmonized to 2000 census tract boundaries using methods employed by Brown University's Longitudinal Tract Data Base, which uses a combination of population and areal weighting. Our neighborhood sample excludes 16 census tracts, which have fewer than 50 residents or have zero housing units during the entire period of analysis, resulting in a

\footnotetext{
${ }^{8}$ We estimate that $1-3 \%$ of consumers in the original sample were dropped while a similar share of consumers was added to the panel each year.

9 Wardrip and Hunt (2014) describe these as "fragments." Fragments usually occur when new records are created and subsequently merged with an existing record when the two records correspond to the same individual. Some fragments may also represent fictitious identities that were created to obtain credit fraudulently.

${ }^{10}$ Although census data are less than perfect for identifying neighborhoods undergoing the physical and demographic changes associated with gentrification (Hwang and Sampson, 2014), these data are conveniently available to the public and allow researchers to look at the same geographic space over time across many neighborhoods and/or cities.
} 
sample of 365 census tracts. Following most existing approaches, we use a threshold strategy for which we identify neighborhoods as being eligible to gentrify at the beginning of a time period and then assess and compare changes among these eligible neighborhoods over a given time period.

We consider tracts to be gentrifiable if they had a median household income below the citywide median at the beginning of the period of analysis. ${ }^{11}$ By definition, in order for tracts to gentrify, they have to be lower-income at the beginning of the period. Given that our study focuses on the changing affordability of neighborhoods and residential mobility outcomes, we measured gentrification by shifts in both housing prices and the socioeconomic status of residents. We include both criteria to deal with issues with past strategies of misidentifying gentrification in neighborhoods experiencing housing price spillovers without demographic changes (Waldorf, 1991).

We consider a tract to be gentrifying over a time period if it was gentrifiable at the beginning of the time period and experienced both an above citywide median percentage increase in either its median gross rent or median home value and an above citywide median increase in its share of college-educated residents. ${ }^{12}$ We rely on housing values and rents because they reflect the quality of various amenities and investment in the neighborhood, and we include changes in either rents or home values because these changes do not necessarily occur in step with each other but nonetheless indicate changing affordability in a previously lowincome neighborhood. Additionally, we rely on increases in the share of college-educated residents rather than incomes to include neighborhoods with increases in young professionals and other groups who may have relatively lower incomes, such as artists, but have higher socioeconomic status than preexisting residents and to better distinguish an influx of new residents from incumbent upgrading (Freeman, 2005). ${ }^{13}$

Because the CCP data used in this study track individuals from 2002 to 2014, our analytic sample only includes tracts that were gentrifiable based on their median household incomes in the year 2000. We consider tracts to be gentrifying if they met the criteria listed previously between 2000 and 2013, ${ }^{14}$ and we consider a neighborhood to be nongentrifying if it was gentrifiable in 2000 and did not meet the previously listed criteria. Of Philadelphia's 365 tracts with substantial population sizes, we categorized 56 of its 184 gentrifiable tracts as gentrifying.

Gentrification is also a dynamic process that occurs at varying paces and takes place in a stage-like process. The pace and stage of gentrification may affect the likelihood of displacement (Freeman et al., 2015). Therefore, we also constructed gentrification categories to assess these differences. We categorize tracts that gentrified either from 1990-2000 or

\footnotetext{
${ }^{11}$ We also constructed measures using the metropolitan area median income as the threshold, but, in Philadelphia, where the metropolitan area median household income far exceeds that of the incomes within Philadelphia, at least $80 \%$ of the tracts in any given decade are considered to be gentrifiable using this threshold. Thus, we present results using the citywide median as the threshold. ${ }_{12}$ Results are similar using metropolitan-wide median increases as the thresholds.

${ }^{13}$ Also including above citywide median percent increases in median incomes only added one additional census tract to the pool of gentrifying neighborhoods. Eight fewer tracts are defined as gentrifying when we restrict by rent or home value changes in addition to education.

${ }^{14}$ We use 2013 for simplification; data for most indicators are actually based on the 2009-2013 ACS data.
} 
from 1980-2000 according to the same criteria, were gentrifiable in 2000, and were gentrifying from 2000-2013 as continued gentrification. ${ }^{15}$ We include the 20-year period from 1980-2000 because earlier gentrification tended to occur more slowly (Newman and Wyly, 2006). These tracts are generally in the more advanced stages of gentrification during our study period. For tracts that were gentrifying from 2000-2013 but were not gentrifying before 2000, we classify them into three categories (weak gentrification, moderate gentrification, and intense gentrification) to indicate the pace of gentrification in these areas based on their quartiles of median rent prices or home values according to the 2009-2013 ACS 5-year estimates. ${ }^{16}$ Figure 2 presents maps of Philadelphia census tracts and the binary and categorical gentrification categories, respectively, and Table 1 provides a detailed description of these categories.

Table 2 shows the neighborhood conditions of gentrifying, nongentrifying, and nongentrifiable neighborhoods in Philadelphia in 2000 and how they changed between 2000 and 2013. While median household incomes, age, and rents were similar between gentrifying and nongentrifying neighborhoods in the year 2000, gentrifying neighborhoods had higher shares of whites, renters, college-educated residents, and median home values than nongentrifying neighborhoods but much lower values for these characteristics compared with nongentrifiable neighborhoods. Home values, rents, and educational attainment levels - the three dimensions used to define gentrifying neighborhoods increased more steeply in gentrifying neighborhoods than in nongentrifying neighborhoods. Moreover, while the average increase in median household income was $41.9 \%$ from 2000 to 2013 in gentrifying neighborhoods, the average median household income decreased by $18.2 \%$ in nongentrifying neighborhoods. There was also a significant decline in the poverty rate of 4.3 percentage points in neighborhoods classified as gentrifying, while there was an increase of 4.8 percentage points in nongentrifying neighborhoods.

In addition, gentrifying neighborhoods recorded an overall increase in their total population (2.3\%) and non-Hispanic white population (23\%) from 2000 to 2013. In contrast, lowerincome neighborhoods that did not gentrify experienced a population loss (1.9\%) and a significant loss of non-Hispanic whites (31.7\%) during the same period. At the same time, the median age of residents in gentrifying neighborhoods declined by 0.7 years, while the median age of those in nongentrifying neighborhoods increased by 0.4 years. These patterns are consistent with what we might expect in gentrifying neighborhoods. Further, other distinctive characteristics that make neighborhoods more likely to gentrify than others, such as proximity to institutions and central location, may influence mobility rates in gentrifying and nongentrifying neighborhoods. We describe how we account for these differences in our analyses below.

\footnotetext{
${ }^{15}$ Separate categorization of tracts that gentrified either from 1990-2000 or from 1980-2000 and were not gentrifying from 20002013 yielded no differences from other nongentrifying tracts.

16 Most tracts categorized as continued gentrification had median rent prices or home values in the top quartile. Categorizing these tracts as weak, moderate, or intense gentrification produced similar substantive results as those presented in Table 5.
} 


\section{Methods}

In our first set of analyses, we compare the residential mobility rates of residents in gentrifying neighborhoods with those in nongentrifying neighborhoods, excluding nongentrifiable neighborhoods from the analysis. The dependent variable is whether or not a resident makes an interneighborhood move (MOVE) between year $t-1$ and year $t$. The key independent variable of interest is our gentrification measure. We use binary and categorical versions of our measure in separate analyses. The unit of analysis is individuals who are in the original 5\% CCP sample (instead of other members from the same household). This helps preclude counting moves by members of the same household more than once. ${ }^{17}$ The total number of observations of those living in either gentrifying or nongentrifying neighborhoods is about 23,000 per year, resulting in more than 250,000 person-years over the entire study period.

The literature suggests a long list of factors that could influence residential mobility, including socioeconomic status, life cycle factors (age, marital status, family status), housing satisfaction (e.g., crowding, unit condition), tenure status, unanticipated changes (e.g., employment status shifts, financial problems), and so on (e.g., Crowder, Pais, and South, 2012; Kan, 1999; Kendig, 1984). Using information available in the CCP data, we construct the following control variables: an individual's initial risk score (at year $t-1$ ), an individual's initial age category, the number of household members with credit reports and SSNs (categorical), whether the individual or any household member has at least one mortgage, and whether the individual or any household member has at least one seriously delinquent (90+ days) account. The risk scores provide a summary measure of an individual's financial health and reflect a dimension of an individual's socioeconomic status. Age serves as a proxy for an individual's stage in the life cycle. The number of household members with credit reports and SSNs indicates the number of adults in the household, which may indicate overcrowding. ${ }^{18}$ Having no mortgage in a household is used as a rough proxy for renters. ${ }^{19}$ Finally, delinquency indicates if there are unexpected financial problems that provoke moves - a strong predictor of residential mobility for those who do not plan to move (Kan, 1999). Although some of these variables are imperfect measures and there are likely some unobserved factors that can prompt a residential move not due to gentrification, such as an employment or marital status change, we can at least control for some of the most important factors associated with residential mobility and observe patterns across various strata of residents.

We further control for tract-level poverty rates, homeownership rates, and the share of nonHispanic blacks, based on interpolated measures using 2000 Census data and 2009-2013 ACS 5-year estimates, ${ }^{20}$ as well as distance measures (distance to City Hall and to two major universities, University of Pennsylvania and Temple University). Whether or not

\footnotetext{
${ }^{17}$ A small share (about 5\%) of households has multiple householders in the original 5\% CCP sample. The results are similar when we exclude individuals in the same household.

${ }^{18}$ Results are nearly identical to those presented when we consider all households with three or more individuals with credit reports in a single category.

${ }^{19}$ According to the ACS, about 50-60\% of households in Philadelphia are homeowners, and about $40 \%$ of owner-occupied units do not have a mortgage. Thus, approximately two-thirds of the individuals without mortgages in our sample are likely renters.

${ }^{20}$ The main results are similar when we use noninterpolated census measures from the 2000 Census.
} 
neighborhoods gentrify and the degree to which they gentrify varies by these characteristics (Hwang and Sampson, 2014). We do not include further neighborhood controls because the goal of our analysis is to examine differential mobility patterns between gentrifying and nongentrifying neighborhoods among residents — not to identify an independent causal effect of gentrification by controlling for all factors that account for differences between which neighborhoods gentrify and which ones do not. Table 3 illustrates the means of the variables used in the analysis by the gentrification status of an individual's origin tract.

We use the following linear probability model to estimate the effect of gentrification on the likelihood of moving:

$\operatorname{Pr}\left(\operatorname{MOVE}_{i t}\right)=\alpha+\beta * \operatorname{GENTRIFY}_{i, t-1}+\gamma * X_{i, t-1}+\delta * \mathrm{NBHD}_{i, t-1}+\zeta * \operatorname{DISTANCE}_{i, t-1}+\eta * \mathrm{YEAR}_{t}$

where:

- $M O V E_{i t}$ is an indicator variable for whether individual $i$ moves to a different census tract from year $t-1$ to year $t$.

- $\quad$ GENTRIFY $Y_{i, t-1}$ is the gentrification measure (binary or categorical).

- $\quad X_{i, t-1}$ includes the set of individual/household characteristics described previously, such as risk score, individual age, household size, mortgage status, and the existence of serious delinquent accounts.

- $\quad N B H D_{i, t-1}$ includes a set of neighborhood indicators (tract poverty rate, homeownership rate, share of non-Hispanic African Americans).

- $\quad$ DISTANCE $E_{i, t-1}$ includes distance measures from $i$ 's origin census tract centroid to the city center and major institutions.

- $Y E A R_{t}$ is the year dummy for a particular cohort.

For ease of interpretation of the coefficients, particularly for interaction terms of different independent variables, we use linear probability regression models, rather than logistic regression models, which are typically used for binary dependent variables. ${ }^{21}$

To assess if residents that move from gentrifying neighborhoods are more likely to move to lower-income neighborhoods, we use a dependent variable indicating whether a resident moves to a neighborhood in a lower income quintile than their origin neighborhood. We use neighborhood household income quintiles, instead of the absolute values of neighborhood income, to compare the relative income level of different neighborhoods. The income quintiles are based on the median incomes of all gentrifiable neighborhoods, which were linearly interpolated based on the 2000 Census and 2009-2013 ACS values for the years between 2000 and 2009. These analyses are restricted to movers in the sample, and we also include the median household income of each mover's origin neighborhood as a control variable. ${ }^{22}$ Given our interest in residential displacement, which, in the context of

\footnotetext{
${ }^{21}$ The results from logistic regressions are very similar and are available upon request.
} 
gentrification, implies an involuntary move for residents who are unable to bear the rising costs of the neighborhood, we examine if the mobility rates and destinations for residents who are more vulnerable to involuntary moves are different from similar residents in nongentrifying neighborhoods. To do this, we assess whether gentrification is associated with elevated mobility rates and elevated mobility downward for residents with low risk scores, residents with no mortgages, or low-score residents without mortgages. Though low risk scores do not necessarily reflect low-income status, individuals with low risk scores have either little or poor credit history and were often hit harder by the Great Recession; thus, they may be more vulnerable to financial challenges and subsequently displacement and disadvantages in the housing market. Likewise, renters, who are more likely to have low or reduced incomes or have much less control over their residential units in gentrifying neighborhoods, respectively, may be more susceptible to displacement. Further, homeowners may be able to withstand the increased cost of living and housing, especially since Philadelphia homeowners did not experience drastic property tax increases during our study period. We include interaction terms for individuals' risk scores and mortgage status with the gentrification status of individuals' neighborhoods to test whether these groups are more likely to move or are more likely to move to lower-income neighborhoods relative to similar residents in nongentrifying neighborhoods. We also focus particularly on low-score residents without mortgages (about $70 \%$ of low-score residents have no mortgages in our data), who are our best proxy of vulnerable renters ${ }^{23}$ in our analysis.

Lastly, for brevity, we primarily report results from models using pooled data that include all cohorts. Since our data span the Great Recession and the associated housing crisis, however, we further examine if mobility patterns differ by economic cycles. Other studies have implicated the role of the housing boom and bust in gentrification (Hyra and Rugh, 2016). To examine if residential mobility patterns associated with gentrification differ during periods in the economic cycle, we conduct an analysis similar to the one presented already but separate the analysis for the following three periods: the boom years (2003-2007, with the 2005 cohort excluded), the bust years (2008-2010), and the recovery years (2011-2014). We then compare our results across these models.

\section{Empirical Results}

\subsection{Overall Mobility Rates}

A comparison of the annual mobility rates estimated using the CCP data suggests that residents in gentrifying neighborhoods had higher mobility rates compared with those in nongentrifying. As the left panel of Figure 3 illustrates, each year, about 10-15\% of residents between 18-84 years old in gentrifying neighborhoods moved to different neighborhoods, ranging from $2-5$ percentage points higher than those in nongentrifying tracts. However, the right panel of Figure 3 shows that mobility rates among low-score

\footnotetext{
${ }^{22}$ The substantive results are similar when we control for the income quintile (instead of the value) of the origin neighborhood or exclude movers from the lowest quintile neighborhoods.

${ }^{23}$ An Urban Institute study suggests that, in the U.S., about $73.2 \%$ of low-credit score individuals (with Vantage scores below 600) without a mortgage are likely to be renters (the rest are likely to be owners who have no or have already paid off their mortgages). For the whole population (18 years or older), the share is $68.6 \%$ ( $\mathrm{Li}$ and Goodman, 2016). According to the ACS, about $40 \%$ of owneroccupied units in Philadelphia do not have a mortgage.
} 
(below 580) residents in gentrifying neighborhoods were only slightly higher than low-score residents in nongentrifying neighborhoods.

Regression results shown in Table 4 predicting the probability of moving after controlling for individual- and neighborhood-level characteristics confirm that residents in gentrifying neighborhoods have a slightly higher probability of moving than residents in nongentrifying neighborhoods in general. ${ }^{24}$ Living in a gentrifying neighborhood is associated with a 0.4 percentage point increase in the probability of moving (as indicated by the coefficient of the gentrify variable reported in the first row and column in Table 4). Given that the annual mobility rate of residents in Philadelphia is about $10 \%$ over the study period, the magnitude of the difference is quite small.

We then distinguish a move to a neighborhood with a lower median income than the individual's origin neighborhood - a downward move - from other moves (moving up or moving to similar income neighborhoods). At the aggregate level, the results displayed in columns 3 and 4 in the first row of Table 4 do not provide significant evidence of downward mobility for residents moving from gentrifying neighborhoods compared with those moving from nongentrifying neighborhoods in general. The coefficient for the gentrify variable is close to zero $(-0.2 \%)$ and insignificant.

Overall, the results show that, at the aggregate level, residents in gentrifying neighborhoods have a slightly higher probability of moving compared with similar residents in nongentrifying neighborhoods, but movers are no more likely to move to lower-income neighborhoods. These results may seem counterintuitive. However, movers from gentrifying neighborhoods are quite heterogeneous, consisting of many younger and high-score residents moving to more expensive neighborhoods, in addition to low-score residents. In fact, $58 \%$ of high-score (750 and above) movers left the city and moved to the suburbs or other states, while only $31 \%$ of low-score movers did so.

\subsection{Mobility for Vulnerable Residents}

The analysis of the subgroups that we expect are vulnerable to displacement in this subsection underscores the heterogeneity of mobility from gentrifying neighborhoods. Table 4 also reports the results for the probability of moving and moving to a lower-income neighborhood, respectively, from a series of linear probability models that include interaction terms between the gentrification status of residents' neighborhoods and individual-level indicators that distinguish residents that may be vulnerable to displacement in the context of gentrification (low-score individuals, individuals without mortgages, or low-score individuals without mortgages). ${ }^{25}$ Here we focus our interpretation on the sum of the coefficients of "gentrify" and "gentrify \& score <580' (or "gentrify \& no mortgage"),

\footnotetext{
${ }^{24}$ Other control variables in the models of residential mobility generally perform as expected. Age, household size, having a mortgage, serious delinquency on at least one account, year dummies, and neighborhood controls are important predictors of whether someone moves.

${ }^{25}$ We also considered elderly residents in other analyses but found low rates of mobility among this population. While elderly residents may be less able to afford rising living and housing costs, younger residents are generally more residentially mobile due to life cycle patterns. We also conducted analysis for the long-term residents for the 2006 cohort and later, and the results suggest longterm residents are no more likely to move but are more likely to move downward when they cannot stay. Results are available upon request.
} 
which indicates how the vulnerable individuals fare relative to similar individuals in nongentrifying neighborhoods. The sums of these coefficients and their significance are listed in the Table 4 the coefficients in each regression model. ${ }^{26}$ The sums of the coefficients discussed below are significant at the 0.1 level or higher ( 0.05 or 0.01 levels).

First, the results suggest that the low-score residents and low-score residents without mortgages in gentrifying neighborhoods are generally no more likely to move than similar residents in nongentrifying neighborhoods. These residents have lower probabilities of moving (about 0.7 percentage points lower) compared with similar residents residing in nongentrifying neighborhoods once we control for individual- and neighborhood-level characteristics. Residents without mortgages in gentrifying neighborhoods, many of whom are likely to be quite mobile and more advantaged renters, have a probability of moving 0.7 percentage points $(-0.9 \%+1.6 \%)$ higher than similar residents in nongentrifying neighborhoods.

Results further suggest that, among all movers, low-score movers and low-score movers without mortgages are generally more likely to move to lower-income neighborhoods. As the second set of columns in Table 4 shows, the probability of moving to lower-income neighborhoods for low-score movers moving out of gentrifying neighborhoods is about 2.4 percentage points $(-5.0 \%+7.4 \%)$ higher than for similar residents in nongentrifying neighborhoods. To put this in context, an increase of 2.4 percentage points would represent a $14.4 \%$ increase relative to the average share $(16.7 \%)$ of movers from nongentrifying neighborhoods moving to lower-income tracts. For low-score residents without mortgages, the results are nearly the same. The sum of the coefficients for movers without mortgages in general is insignificant, which is not surprising because this subgroup includes many more advantaged movers who are more likely to move to more expensive neighborhoods.

\subsection{Mobility for Vulnerable Residents in Different Types of Gentrifying Neighborhoods}

Next, we examine how our best proxy of vulnerable individuals — low-score residents without mortgages - fare in neighborhoods with different levels of gentrification relative to similar individuals in nongentrifying neighborhoods. We achieve this by focusing on residents without mortgages only and include interaction terms between low-score status (below 580 or not) and types of gentrification. The results, which are presented in Table 5, show that low-score residents without mortgages are generally no more likely to move out of gentrifying neighborhoods. The sums of the coefficients of the gentrification category variable and the interaction variable are either negative (for "weak gentrification") or insignificant (for "moderate gentrification" and "intense gentrification"). The only exception is a slightly higher mobility rate ( 0.8 percentage points higher and significant at the 0.1 level) for residents in neighborhoods with "continued gentrification" compared with similar residents in nongentrifying neighborhoods. In contrast, for higher-score (580+) residents without mortgages, the probability of moving is much higher in neighborhoods that gentrified more rapidly ("intense gentrification," 4.5 percentage points higher) or neighborhoods experiencing "continued gentrification" (about 2.9 percentage points higher).

\footnotetext{
${ }^{26}$ We used an F-test to test whether the sum of two coefficients is significantly different from zero.
} 
The coefficients are either negative or insignificant for neighborhoods with weak and moderate gentrification, suggesting that the relatively higher mobility in gentrifying neighborhoods in Philadelphia are largely driven by more financially advantaged residents in neighborhoods with more intense levels of gentrification or neighborhoods experiencing gentrification for a long time.

When more vulnerable residents (those low-score movers without mortgages) move, those who move from neighborhoods with a moderate or intense level of gentrification or those neighborhoods that were gentrifying before 2000 are more likely to move to lower-income neighborhoods. The magnitude of the sums increase from 2.9 percentage points for "moderate gentrification" to 4.4 percentage points for "intense gentrification" and 4.8 percentage points for "continued gentrification." The coefficient is insignificant for lowscore, no-mortgage movers from neighborhoods with weak gentrification. The results clearly indicate that when vulnerable residents are unable to remain in the neighborhood, those in neighborhoods with higher levels of gentrification face a higher risk of moving to an economically worse-off neighborhood.

\subsection{Mobility of Vulnerable Residents in Different Economic Cycles}

To examine how the mobility patterns of vulnerable residents changed over time, we replicated the mobility analysis for the following three cohorts: the boom years (20032007), the bust years (2008-2010), and the recovery years (2011-2014). Regression results are summarized in Table 6 . The results suggest that low-score residents and low-score residents without mortgages in gentrifying neighborhoods are no more likely to move than similar residents in nongentrifying neighborhoods across different periods and are sometimes less likely to move. For example, low-score residents without mortgages in gentrifying neighborhoods are slightly less likely to move than similar residents in nongentrifying neighborhoods during the boom years (about 1.6 percentage points less likely; see last row in Table 6), with the difference becoming insignificant and close to zero during the bust years (2008-2010) and the more recent recovery years (2011 and after). Residents without mortgages, however, are more likely to move from gentrifying neighborhoods than nongentrifying neighborhoods in the bust and recovery years.

We further find that low-score movers and low-score movers without mortgages are more likely to move to lower-income neighborhoods in the more recent recovery years (2011 and after), suggesting vulnerable movers from gentrifying neighborhoods face a higher risk of moving downward in these years. The probability of moving downward for these residents is insignificant for the other two periods, though the relationship is positive (based on the sums of the coefficients) for both periods. During the bust years (2008-2010), the differences in the probability of downward mobility between these movers from gentrifying and nongentrifying neighborhoods are close to zero. One possible explanation is that because many low-income and minority neighborhoods were hit harder by the most recent housing crisis (Mian and Sufi, 2009), vulnerable movers from nongentrifying neighborhoods may have faced more challenges during the economic downturn; alternatively, the pace of gentrification may have slowed or been stagnant during the housing crisis, thereby mitigating residential displacement in gentrifying neighborhoods during this period. For

Reg Sci Urban Econ. Author manuscript; available in PMC 2017 November 01. 
residents without mortgages, the differences between those in gentrifying and nongentrifying neighborhoods are insignificant across all three periods.

\subsection{Robustness Checks}

As mentioned earlier, there are concerns on how to operationalize gentrification, the representativeness of the $\mathrm{CCP}$ data of certain subpopulations, and the right counterfactual for gentrifying neighborhoods. We conducted additional analyses using alternative gentrification measures, different subsamples, and different control groups to discern how sensitive the results are to some of our analytical decisions. For the sake of brevity, we only discuss general patterns here and only present results for residents without mortgages in Table 7. The main results for this subsample described previously are displayed in the first column and fifth column of Table 7 for the mobility and downward mobility analyses, respectively.

We further restrict the analysis to residents in gentrifying neighborhoods or nongentrifying neighborhoods that are within 0.5 miles from a gentrifying neighborhood to deal with concerns that some nongentrifying neighborhoods are farther from other amenities and have unobserved characteristics that make them less comparable with gentrifying neighborhoods. The sum of the coefficients of the "gentrify" variable and the interaction "gentrify \& score $<580^{\prime}$ ' is statistically significant and the magnitude is quite similar (-0.9 percentage points versus -0.7 percentage points, see column 2 in Table 7). The results are also similar for the analysis of downward mobility ( 3.1 percentage points versus 2.4 percentage points; see column 6 in Table 7).

Second, individuals' risk scores and mobility may be correlated with a third factor, the likelihood of having their addresses updated in a timely manner, which may bias estimates in our analysis. No-score or low-score individuals may have fewer or no credit accounts, lowering the chance of having their addresses updated and then being reported to the credit bureau. We replicated the mobility analysis using individuals with at least two credit accounts only. These individuals are more likely to have timely address updates in our data. The magnitude of the sums of the coefficients are smaller (significant for the mobility analysis and insignificant for the downward mobility analysis) but the signs remain the same (see columns 3 and 7 in Table 7).

Furthermore, as mentioned earlier, the 18-24 year olds are slightly less represented in the CCP data, so we conducted additional analysis to check the robustness of the results by excluding individuals who are 24 years old or younger. The results based on those 25-84 years old only are quite consistent in terms of the direction, significance, as well as the magnitude of the coefficients of the variables of interest (see columns 4 and 8 in Table 7). ${ }^{27}$ Finally, though the results are not included here, when we use alternative gentrification measures, such as a measure considering home values and rents only or a measure that also includes changes in median household income, the results are generally consistent.

${ }^{27}$ While we control for age, another concern is that individuals in their 20 s are highly mobile. We also restricted the analysis to individuals 30-84 years old only, and the results are similar to those presented for ages 25-84 years old. 


\subsection{Summary of Empirical Results}

Overall, the results show that more vulnerable individuals (low-score individuals and lowscore individuals without mortgages) are not necessarily more likely to move from gentrifying neighborhoods than similar residents in nongentrifying neighborhoods, which is consistent with other recent findings (Freeman, 2005; McKinnish et al., 2010; Ellen and O'Regan, 2011). However, vulnerable individuals who move have a higher risk of downward mobility, particularly when they move out of intensely gentrifying neighborhoods or neighborhoods in morep advanced stages of gentrification. The findings generally hold across various robustness tests and restricted samples, and the pattern of downward mobility is more evident in the more recent recovery years. We suspect that there are likely two competing forces for disadvantaged residents in gentrifying neighborhoods, especially those neighborhoods that are gentrifying slowly: Gentrification may be increasing interneighborhood mobility as a result of rising rents and other costs, but some residents may be willing to pay the rising costs of living given the increase in amenities and rising home values that come with gentrification (Freeman, 2005). Further, the prevalence of in-fill development and rehabilitation of vacant properties, as well as the lack of property tax increases, may also have mitigated pressures for disadvantaged residents to move.

Nonetheless, if they are unable to remain in the neighborhood, more vulnerable individuals face a higher risk of moving to an economically worse-off neighborhood, often within the city. If gentrification induces their moves, they likely engage in constrained housing searches, where they face declines in affordable housing options as once affordable neighborhoods gentrify across the city and greater barriers (e.g., landlords who are more selective about tenant credit histories) to leaving the city or moving to similar- or higherincome neighborhoods. Finally, although we control for other factors that are likely associated with residential mobility, we acknowledge that we are limited in our ability to draw conclusions on the causal relationship between gentrification and residential displacement given that characteristics associated with residents' choices to live in gentrifying neighborhoods might also affect how they respond to gentrification.

\section{Conclusions}

This case study of Philadelphia leverages a unique data set to shed light on the heterogeneous consequences of gentrification on residential mobility patterns. Our findings contribute to debates on gentrification and displacement by uncovering important nuances of residential mobility associated with the destinations of movers, vulnerable subpopulations, the pace of gentrification, and economic cycles. Previous studies have not explored these important dimensions of gentrification nor have they examined these patterns as gentrification has grown and expanded relative to its past since the late 1990s.

We find that gentrifying neighborhoods in Philadelphia, especially those in the more advanced stages of gentrification, have higher mobility rates on average compared with nongentrifying neighborhoods, but these movers are more likely to be financially healthier residents moving to higher-quality neighborhoods. Consistent with other recent studies of mobility and gentrification (Ellen and O'Regan, 2011; Freeman, 2005; McKinnish et al., 2010), we generally do not find that more vulnerable residents in gentrifying neighborhoods

Reg Sci Urban Econ. Author manuscript; available in PMC 2017 November 01. 
have elevated rates of mobility. As discussed earlier, Philadelphia has a number of distinct features that may mitigate the pace of residential displacement, such as its high vacancy rates and property tax assessment practices. It is also possible that displacement among vulnerable residents has not yet occurred during the study period or could be better observed when more comprehensive data are available. The slightly higher mobility rates among lowscore residents in neighborhoods already in the more advanced stages of gentrification lend support for this. It is also possible that we do not observe displacement occurring within census tracts, but, if this is the case, localized moves, though still costly, among vulnerable residents in gentrifying census tracts may have less negative consequences for these residents who would still be proximate to the increased amenities that come with gentrification (McKinnish et al., 2010).

When more vulnerable residents move from gentrifying neighborhoods, however, they are more likely than their counterparts in nongentrifying neighborhoods to move to neighborhoods with lower incomes than the neighborhoods from where they move. These results suggest that gentrification redistributes less advantaged residents into less advantaged neighborhoods, contributing to the persistence of neighborhood disadvantage. Therefore, even though we do not observe higher mobility rates among these groups, the results still demonstrate that gentrification can have negative residential consequences for these subpopulations.

Although our data are limited from examining race and ethnicity and other financial indicators and in representing some segments of the population, our data allow us to disaggregate relatively financially independent residents by demographic characteristics and to examine residential destinations. We uncover how mobility in gentrifying neighborhoods in Philadelphia is largely driven by more advantaged residents in neighborhoods that gentrified rapidly or have been gentrifying for a long time, and we are also able to show that residential destinations among movers from gentrifying neighborhoods are uneven, having negative consequences for less advantaged residents. Even though we do not find elevated mobility rates among vulnerable residents, the fact that they are more likely to move to economically worse-off neighborhoods provides support for policies to prevent and mitigate residential displacement.

Altogether, our findings contribute to debates on gentrification and residential displacement by shedding new light on the heterogeneity in mobility rates and destinations across residents in gentrifying neighborhoods, as well as across the pace of gentrification in neighborhoods and economic cycles. Researchers and policymakers should recognize this heterogeneity in understanding gentrification-induced displacement and focus attention on the quality of residential moves and nonmoves for less advantaged residents, rather than only mobility rates, to better understand the consequences of gentrification.

\section{Acknowledgments}

The authors would like to thank Jeffrey Lin, Ingrid G. Ellen, Jacob Faber, Elizabeth Roberto, Robert M. Hunt, Leonard Nakamura, Theresa Singleton, Jung Hyun Choi, Daniel McMillen, anonymous referees, and participants of the 2015 Policy Summit on Housing, Human Capital, and Inequality, the 2016 Population Association of American Annual Meeting, and the 2016 American Real Estate and Urban Economics Association National Conference for helpful comments. This research was supported in part by The Eunice Kennedy Shriver National Institute of Child

Reg Sci Urban Econ. Author manuscript; available in PMC 2017 November 01. 
Health \& Human Development of the National Institutes of Health (Grant No. T32HD007163). The views expressed in this paper are those of the authors and do not necessarily reflect the views of the Federal Reserve Bank of Philadelphia, the Federal Reserve System, or the National Institutes of Health.

\section{References}

Ahlfeldt, Gabriel M. Blessing or Curse? Appreciation, Amenities and Resistance to Urban Renewal. Regional Science and Urban Economics. 2011; 41(1):32-45.

Barton, Michael. An Exploration of the Importance of the Strategy Used to Identify Gentrification. Urban Studies. 2016; 53(1):92-111.

Brevoort, Kenneth P., Grimm, Philipp, Kambara, Michelle. Credit Invisibles and the Unscored. Cityscape. 2016; 18(2):9-33.

Capperis, Sean, Ellen, Ingrid Gould, Karfunkel, Brian. Renting in America's Largest Cities: NYU Furman Center/Capital One National Affordable Rental Housing Landscape. New York University Furman Center for Real Estate and Urban Policy; 2015. http://furmancenter.org/files/ CapOneNYUFurmanCenter__NationalRentalLandscape_MAY2015.pdf

Crowder, Kyle, Pais, Jeremy, South, Scott J. Neighborhood Diversity, Metropolitan Constraints, and Household Migration. American Sociological Review. 2012; 77(3):325-353. [PubMed: 22753955]

Ellen, Ingrid Gould, O'Regan, Katherine M. How Low Income Neighborhoods Change: Entry, Exit, and Enhancement. Regional Science and Urban Economics. 2011; 41(2):89-97.

Freeman, Lance. Displacement or Succession? Residential Mobility in Gentrifying Neighborhoods. Urban Affairs Review. 2005; 40(4):463-491.

Freeman, Lance, Braconi, Frank. Gentrification and Displacement: New York City in the 1990s. Journal of the American Planning Association. 2004; 70(1):39-52.

Freeman, Lance, Cassola, Adele, Cai, Taicheng. Displacement and Gentrification in England and Wales: A Quasi-Experimental Approach. Urban Studies. 2016; 53(13):2797-2814.

Gillen, Kevin C. Philadelphia's Ten-year Property Tax Abatement. Building Industry Association of Philadelphia Report. 2013. http://www.biaofphiladelphia.com/ufiles/abatement_report.pdf

Grier, George, Grier, Eunice E. Urban Displacement: A Reconnaissance. Washington, DC: U.S Department of Housing and Urban Development; 1978.

Gyourko, Joseph, Mayer, Christopher, Sinai, Todd. Superstar Cities. American Economic Journal: Economic Policy. 2013; 5(4):167-199.

Hwang, Jackelyn, Sampson, Robert J. Divergent Pathways of Gentrification: Racial Inequality and the Social Order of Renewal in Chicago Neighborhoods. American Sociological Review. 2014; 79(4): 726-751.

Hyra, Derek A. The Back-to-the-City Movement: Neighborhood Redevelopment and Processes of Political and Cultural Displacement. Urban Studies. 2014; 52(10):1753-1773.

Hyra, Derek A., Rugh, Jacob S. The U.S. Great Recession: Exploring Its Association with Black Neighborhood Rise, Decline and Recovery. Urban Geography. 2016; 37(5):700-726.

Kan, Kamhon. Expected and Unexpected Residential Mobility. Journal of Urban Economics. 1999; 45(1):72-96.

Kendig, Hal L. Housing Careers, Life Cycle, and Residential Mobility: Implications for the Housing Market. Urban Studies. 1984; 21(3):271-283.

Lee, Donghoon, van der Klaauw, Wilbert. Staff Reports 479. Federal Reserve Bank of New York; 2010. An Introduction to the FRBNY Consumer Credit Panel. http://www.newyorkfed.org/ research/staff_reports/sr479.html

William, Lester T., Hartley, Daniel A. The Long Term Employment Impacts of Gentrification in the 1990s. Regional Science and Urban Economics. 2014; 45(C):80-89.

Li, Wei, Goodman, Laurie. Comparing Credit Profiles of American Renters and Owners. Urban Institute; 2016. http://www.urban.org/sites/default/files/alfresco/publication-pdfs/2000652Comparing-Credit-Profiles-of-American-Renters-and-Owners.pdf

McKinnish, Terra, Walsh, Randall, White, T Kirk. Who Gentrifies Low-Income Neighborhoods? Journal of Urban Economics. 2010; 67(2):180-193. [PubMed: 20161532] 
Mian, Atif, Sufi, Amir. The Consequences of Mortgage Credit Expansion: Evidence from the U.S. Mortgage Default Crisis. Quarterly Journal of Economics. 2009; 124(4):1449-1496.

Molloy, Raven, Shan, Hui. The Postforeclosure Experience of U.S. Households. Real Estate Economics. 2013; 41(2):225-254.

Newman, Kathe, Wyly, Elvin K. The Right to Stay Put, Revisited: Gentrification and Resistance to Displacement in New York City. Urban Studies. 2006; 43(1):23-57.

Owens, Ann. Neighborhoods on the Rise: A Typology of Neighborhoods Experiencing Socioeconomic Ascent. City \& Community. 2012; 11(4):345-369.

Pattillo, Mary. Black on the Block: The Politics of Race and Class in the City. Chicago: University of Chicago Press; 2007.

Pew Charitable Trusts. Philadelphia 2011: The State of the City. 2011. http://www.pewtrusts.org/ / media/legacy/uploadedfiles/wwwpewtrustsorg/reports/philadelphia_research_initiative/ philadelphiacitydatapopulationdemographicspdf.pdf

Pew Charitable Trusts. The Actual Value Initiative: Overhauling Property Taxes in Philadelphia. 2012. http://www.pewtrusts.org/ /media/legacy/uploadedfiles/philadelphiapropertytaxespdf.pdf

Schill, Michael H., Nathan, Richard P. Revitalizing America's Cities: Neighborhood Reinvestment and Displacement. Albany, NY: State University of New York Press; 1983.

Spain, Daphne, Reid, John, Long, Larry. Current Population Reports, Series. Vol. 101. U.S Census Bureau; 1980. Housing Successions Among Blacks and Whites in Cities and Suburbs; p. 23

Vigdor, Jacob L. Does Gentrification Harm the Poor? Brookings-Wharton Papers on Urban Affairs. 2002:133-173.

Waldorf, Brigitte S. A Spatial Analysis of Rent Shifts in the Chicago Rental Housing Market, 1970-1980. Urban Geography. 1991; 12(5):450-468.

Wardrip, Keith, Hunt, Robert M. Community Development Studies \& Education Discussion Paper 13-01. Federal Reserve Bank of Philadelphia; 2013. Residential Migration, Entry, and Exit as Seen through the Lens of Credit Bureau Data.

Reg Sci Urban Econ. Author manuscript; available in PMC 2017 November 01. 


\section{Highlights}

- This paper examines the relationship between gentrification and residential mobility from 2002-2014.

- Less advantaged residents are generally no more likely to move from gentrifying neighborhoods.

- However, less advantaged movers are more likely to move to lower-income neighborhoods.

- The mobility patterns vary across gentrification types and economic cycles. 


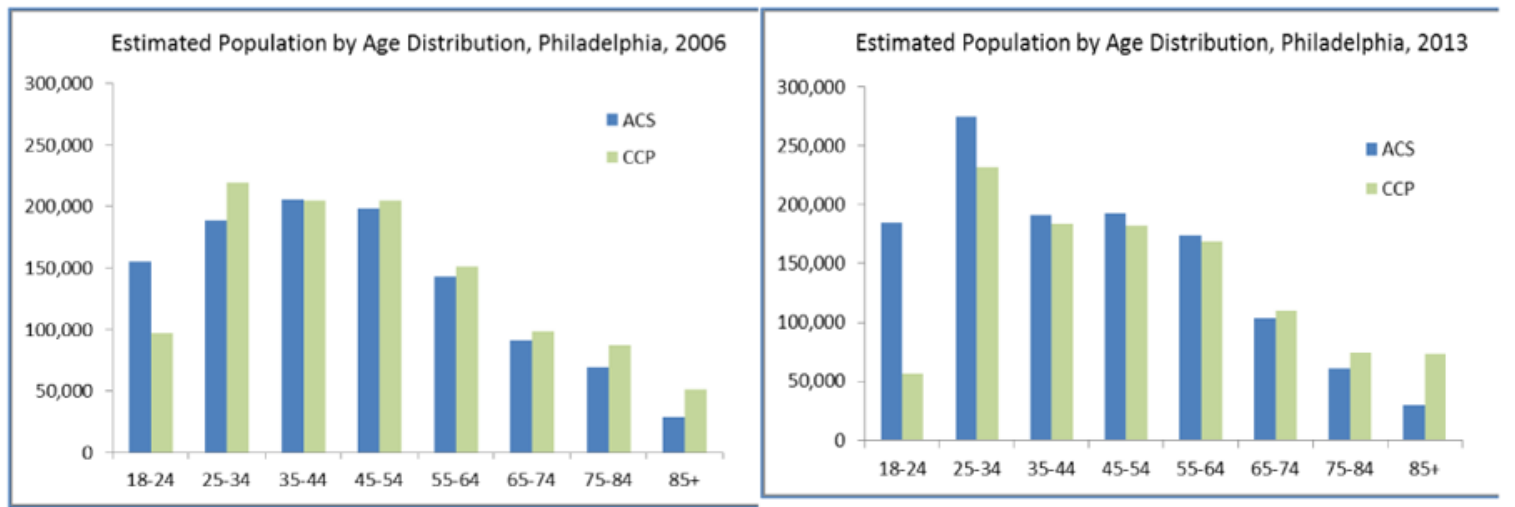

Figure 1. Comparison of Estimated Population by Age Categories based on American Community Survey and CCP Data

Note: Authors' calculations using data from the ACS data in corresponding years and FRBNY Consumer Credit Panel/Equifax. 


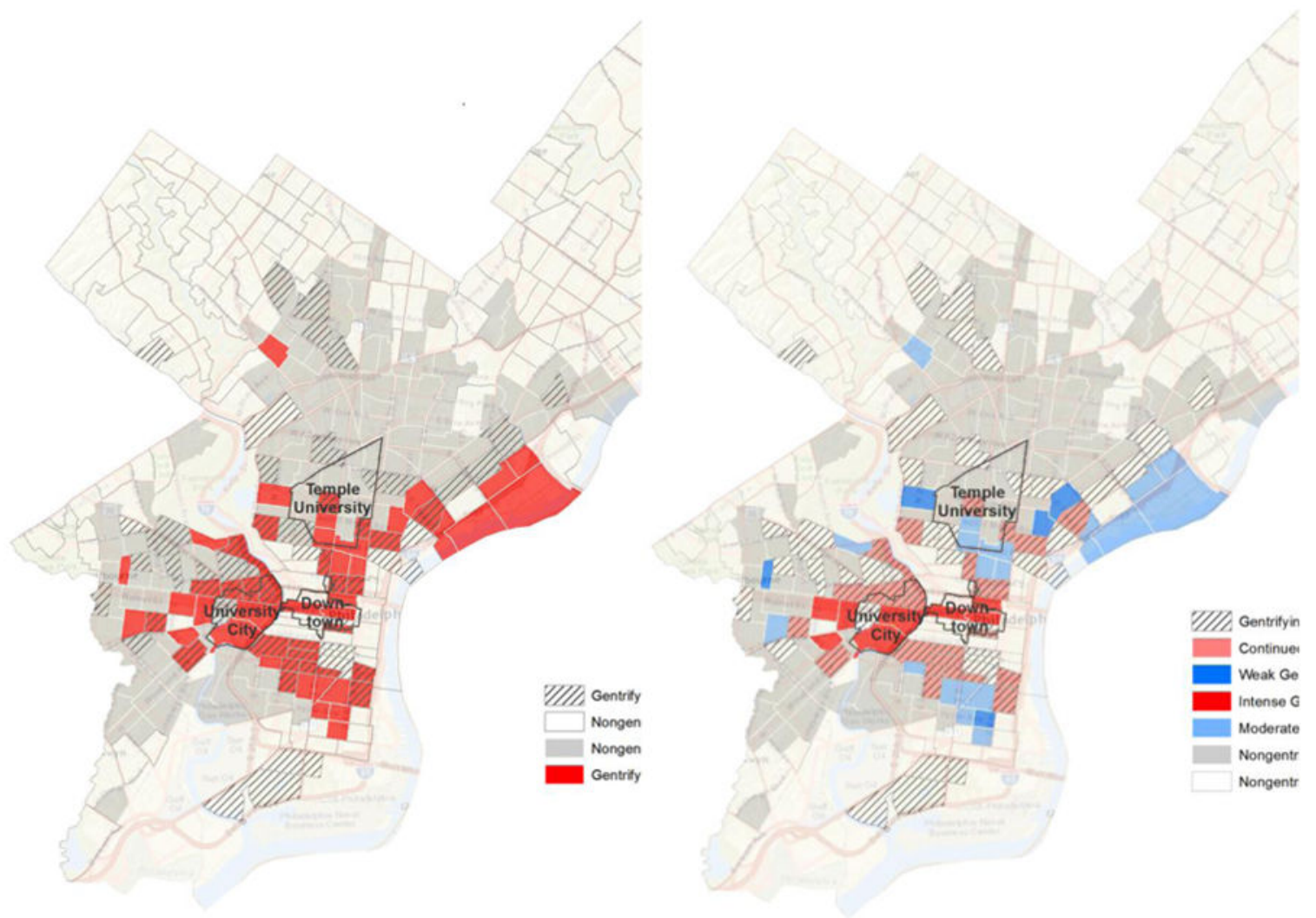

Figure 2. Gentrifying Neighborhoods in the City of Philadelphia (Left: Binary Measure; Right: Categorical Measure)

Source: Authors' definition based on 2000 Census and 2009-2013 ACS data and U.S.

Census TIGER/Line Shapefiles.

Reg Sci Urban Econ. Author manuscript; available in PMC 2017 November 01. 


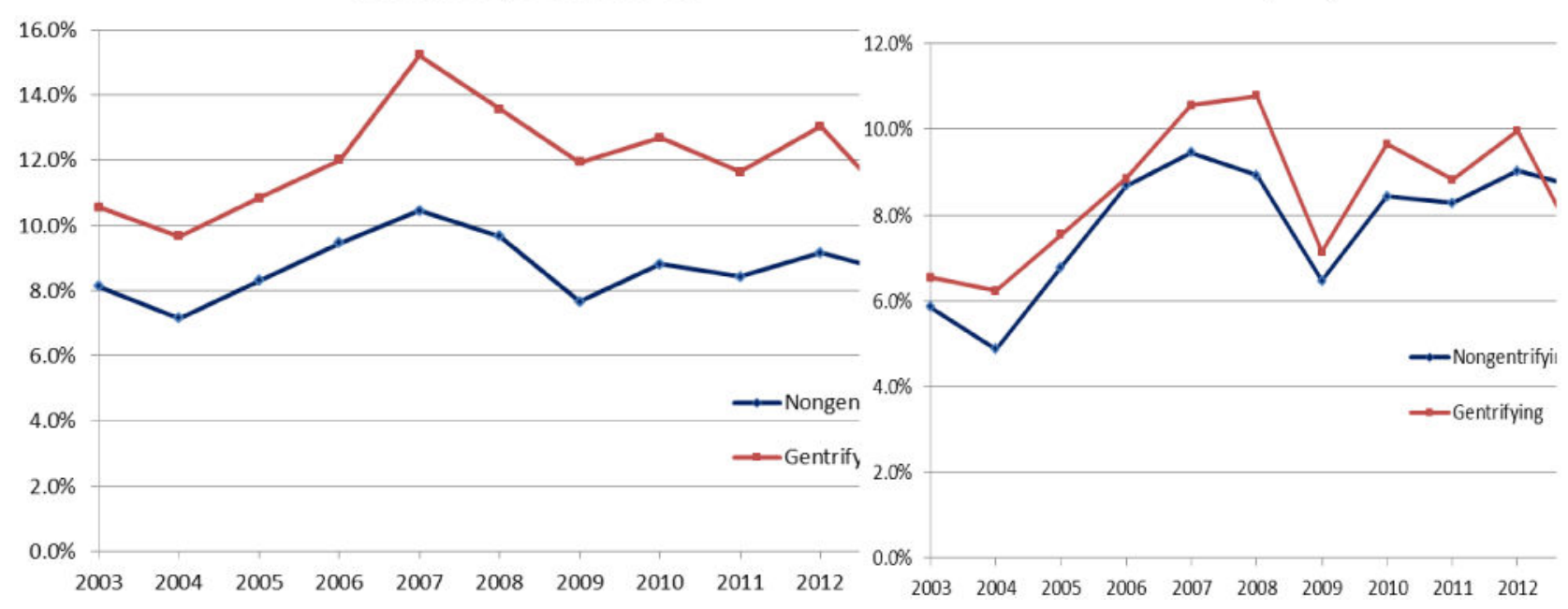

Figure 3. Annual Mobility Rate by Neighborhood Type in Gentrifiable Philadelphia (Left: All Residents; Right: Low-score Residents)

Note: A "mover" is defined as one who lives in a census tract different from where he or she lived one year ago; authors' calculations using data from the FRBNY Consumer Credit Panel/Equifax. 
Table 1

Description of Categorical Gentrification Measure

\begin{tabular}{llcl}
\hline & Categories & \# of Tracts & Explanation \\
\hline Nongentrifiable & Nongentrifiable & 181 & nongentrifiable in 2000 \\
Nongentrifying & Nongentrifying & 105 & nongentrifying, pre-2000 and 2000--2013 \\
& Stalled gentrification & 23 & pre-2000 gentrification and not gentrifying 2000-2013 \\
\multirow{4}{*}{ Gentrifying } & Continued gentrification & 24 & pre-2000 gentrification and gentrifying 2000-2013 \\
& Weak gentrification & 5 & gentrifying but in the bottom quartile of gentrifying tracts for rent and value in \\
& Moderate gentrification & 19 & gentrifying and in the 2nd or 3rd quartile for either rent or value in 2009-2013 \\
& Intense gentrification & 8 & gentrifying and in the top quartile for rent or value in 2009-2013 \\
\hline
\end{tabular}

Source: Authors' calculations use data from 1980, 1990, and 2000 Census and the 2009-2013 American Community Survey. 
Table 2

Neighborhood Characteristics by Gentrification Category

\begin{tabular}{|c|c|c|c|}
\hline Initial Neighborhood Condition, 2000 & Nongentrifying & Gentrifying & Nongentrifiable \\
\hline Total population in 2000 & 555,827 & 209,421 & 745,870 \\
\hline$\%$ of non-Hispanic white in 2000 & $16.0 \%$ & $33.8 \%$ & $64.8 \%$ \\
\hline$\%$ of non-Hispanic black in 2000 & $65.4 \%$ & $50.2 \%$ & $24.9 \%$ \\
\hline$\%$ of renters in 2000 & $42.7 \%$ & $53.5 \%$ & $33.6 \%$ \\
\hline Median household income in 2000 (in 2000 \$) & $\$ 21,895$ & $\$ 21,042$ & $\$ 43,366$ \\
\hline$\%$ of college-educated & $8.4 \%$ & $16.5 \%$ & $27.8 \%$ \\
\hline Median age in 2000 & 32 & 33 & 38 \\
\hline Median rent in 2000 (in $2000 \$$ ) & $\$ 560$ & $\$ 577$ & $\$ 801$ \\
\hline Median value in 2000 (in $2000 \$$ ) & $\$ 40,560$ & $\$ 58,530$ & $\$ 103,300$ \\
\hline \multicolumn{4}{|l|}{ Change in Neighborhood Indicators, 2000-2013 } \\
\hline$\%$ change in total population & $-1.9 \%$ & $2.3 \%$ & $3.5 \%$ \\
\hline$\%$ change in non-Hispanic white & $-31.7 \%$ & $22.8 \%$ & $-14.5 \%$ \\
\hline$\%$ change in non-Hispanic black & $-4.7 \%$ & $-26.5 \%$ & $17.7 \%$ \\
\hline Average $\%$ change in median household income & $-18.2 \%$ & $41.9 \%$ & $-7.2 \%$ \\
\hline Average change in $\%$ college-educated & $1.5 \%$ & $16.4 \%$ & $6.3 \%$ \\
\hline Change in median age & 0.35 & -0.69 & 0.35 \\
\hline Average change in poverty rate $(\%)$ & $4.8 \%$ & $-4.3 \%$ & $3.8 \%$ \\
\hline Average $\%$ change in median home value & $65.8 \%$ & $163.3 \%$ & $61.0 \%$ \\
\hline Average $\%$ change in median rent & $5.5 \%$ & $42.6 \%$ & $12.9 \%$ \\
\hline$\%$ change in the share of cost-burdened & $10.4 \%$ & $5.3 \%$ & $11.7 \%$ \\
\hline Number of tracts & 128 & 56 & 181 \\
\hline
\end{tabular}

Source: Authors' calculations using data from 2000 Census and 2009-2013 American Community Survey. Note: A total of 16 tracts were excluded because of no or extremely small population. 


\section{Descriptive Statistics}

Table 3

\begin{tabular}{|c|c|c|c|c|}
\hline Variable & All Residents & Nongentrifying Tracts & Gentrifying Tracts & Nongentrifiable Tracts \\
\hline Moved in one year & $10.1 \%$ & $9.0 \%$ & $12.2 \%$ & $10.3 \%$ \\
\hline moved within city & $5.9 \%$ & $6.1 \%$ & $7.1 \%$ & $5.5 \%$ \\
\hline moved out of city & $4.3 \%$ & $2.9 \%$ & $5.1 \%$ & $4.9 \%$ \\
\hline moved to a lower-income tract (movers) & $21.0 \%$ & $16.7 \%$ & $17.5 \%$ & $24.3 \%$ \\
\hline moved to a higher-income tract (movers) & $41.4 \%$ & $66.3 \%$ & $57.5 \%$ & $23.6 \%$ \\
\hline Nongentrifying neighborhoods & $33.0 \%$ & & & \\
\hline Gentrifying neighborhoods & $13.2 \%$ & & & \\
\hline Nongentrifiable neighborhoods & $53.9 \%$ & & & \\
\hline \multicolumn{5}{|l|}{ Risk score } \\
\hline missing & $9.2 \%$ & $13.6 \%$ & $10.9 \%$ & $6.2 \%$ \\
\hline $290-579$ & $27.1 \%$ & $38.8 \%$ & $27.1 \%$ & $19.9 \%$ \\
\hline $580-649$ & $17.7 \%$ & $20.7 \%$ & $17.9 \%$ & $15.7 \%$ \\
\hline $650-749$ & $23.2 \%$ & $17.5 \%$ & $24.1 \%$ & $26.5 \%$ \\
\hline $750+$ & $22.8 \%$ & $9.4 \%$ & $20.1 \%$ & $31.7 \%$ \\
\hline Mean risk score (standard deviations) & $650.8(112.0)$ & $604.6(101.6)$ & $646.4(109.3)$ & $677.9(109.6)$ \\
\hline \multicolumn{5}{|l|}{ Age } \\
\hline $18-24$ & $8.6 \%$ & $10.0 \%$ & $9.0 \%$ & $7.7 \%$ \\
\hline $25-34$ & $21.4 \%$ & $20.8 \%$ & $25.2 \%$ & $20.9 \%$ \\
\hline $35-44$ & $18.9 \%$ & $19.5 \%$ & $19.4 \%$ & $18.4 \%$ \\
\hline $45-54$ & $18.8 \%$ & $19.5 \%$ & $17.3 \%$ & $18.8 \%$ \\
\hline $55-64$ & $14.9 \%$ & $14.5 \%$ & $13.3 \%$ & $15.5 \%$ \\
\hline$\checkmark 65$ & $17.4 \%$ & $15.8 \%$ & $15.8 \%$ & $18.8 \%$ \\
\hline \multicolumn{5}{|l|}{ Household size (those with credit info) } \\
\hline 1 & $19.0 \%$ & $19.4 \%$ & $24.7 \%$ & $17.3 \%$ \\
\hline 2 & $28.0 \%$ & $25.1 \%$ & $27.8 \%$ & $29.9 \%$ \\
\hline 3 & $23.4 \%$ & $23.0 \%$ & $20.7 \%$ & $24.2 \%$ \\
\hline 4 & $14.9 \%$ & $15.6 \%$ & $12.8 \%$ & $14.9 \%$ \\
\hline $5+$ & $14.8 \%$ & $16.9 \%$ & $14.0 \%$ & $13.7 \%$ \\
\hline Having 1+ mortgages (whole household) & $32.1 \%$ & $19.2 \%$ & $22.6 \%$ & $42.4 \%$ \\
\hline $\begin{array}{l}\text { Having 1+90+day delinquent accounts (whole } \\
\text { household) }\end{array}$ & $20.6 \%$ & $27.0 \%$ & $19.6 \%$ & $17.0 \%$ \\
\hline \multicolumn{5}{|l|}{ Length in the tract } \\
\hline Less than 2 years in the tract & $11.8 \%$ & $11.1 \%$ & $15.2 \%$ & $11.5 \%$ \\
\hline $2-4$ years in the tract & $15.5 \%$ & $15.5 \%$ & $17.6 \%$ & $14.9 \%$ \\
\hline $5+$ years in the tract & $72.7 \%$ & $73.5 \%$ & $67.2 \%$ & $73.6 \%$ \\
\hline Distance to City Hall (miles) & 5.6 & 4.2 & 2.1 & 7.3 \\
\hline Distance to the university (miles) & 4.2 & 2.5 & 1.7 & 5.9 \\
\hline Person years (2002-2003; 2005-2013) & 550,261 & 181,453 & 72,454 & 296,354 \\
\hline
\end{tabular}

Note: Authors' calculations using data from 2000 Census, 2009-2013 American Community Survey, and data from the FRBNY Consumer Credit Panel/Equifax. These figures are for the full set of pooled person-years and therefore can include the same individual more than once. 
Table 4

Results Estimating the Effect of Gentrification (Binary) on Residential Mobility for Different Subpopulations

\begin{tabular}{|c|c|c|c|c|}
\hline & \multicolumn{2}{|c|}{ Move (Any Move) as the Outcome } & \multicolumn{2}{|c|}{ Move Downward as the Outcome (Movers) } \\
\hline & Coefficient & Standard Error & Coefficient & Standard Error \\
\hline \multicolumn{5}{|l|}{ Binary Gentrification Results } \\
\hline Gentrify (binary) & $0.004^{* *}$ & 0.002 & -0.002 & 0.007 \\
\hline \multicolumn{5}{|c|}{ Gentrification \& risk score (Ref: Nongentrify \& Score 750+) } \\
\hline Gentrify & -0.005 & 0.004 & $-0.050^{* * *}$ & 0.016 \\
\hline Score 650-749 & $0.011^{* * *}$ & 0.003 & $0.041^{* * *}$ & 0.012 \\
\hline Score 580-649 & 0.003 & 0.003 & $0.078^{* * * *}$ & 0.012 \\
\hline Score $<580$ & $-0.028^{* * * *}$ & 0.002 & $0.121^{* * *}$ & 0.012 \\
\hline Gentrify \& Score $650-749$ & $0.036^{* * * *}$ & 0.004 & 0.023 & 0.017 \\
\hline Gentrify \& Score 580-649 & $0.015^{* * *}$ & 0.004 & $0.053^{* * *}$ & 0.017 \\
\hline Gentrify \& Score $<580$ & -0.002 & 0.004 & $0.074^{* * *}$ & 0.016 \\
\hline Gentrify + Gentrify \& Score $<580$ & $-0.007^{* * *}$ & & $0.024^{* *}$ & \\
\hline \multicolumn{5}{|c|}{ Gentrification \& mortgage status (Ref: Nongentrify \& Mortgage) } \\
\hline Gentrify & $-0.009^{* * *}$ & 0.003 & $-0.032^{* * *}$ & 0.012 \\
\hline No mortgage & 0.002 & 0.002 & $0.028^{* * *}$ & 0.007 \\
\hline Gentrify \& No mortgage & $0.016^{* * *}$ & 0.003 & $0.037^{* * *}$ & 0.012 \\
\hline Gentrify + Gentrify \& No mortgage & $0.007^{* * *}$ & & 0.005 & \\
\hline \multicolumn{5}{|c|}{ Gentrification \& risk score (for residents without mortgages) } \\
\hline Gentrify & 0.003 & 0.004 & $-0.058^{* * *}$ & 0.019 \\
\hline Score $650-749$ & $0.017^{* * *}$ & 0.003 & $0.042^{* * *}$ & 0.015 \\
\hline Score 580-649 & $0.008^{* * *}$ & 0.003 & $0.076^{* * *}$ & 0.015 \\
\hline Score $<580$ & $-0.026^{* * *}$ & 0.003 & $0.125^{* * *}$ & 0.014 \\
\hline Gentrify \& Score 650-749 & $0.037^{* * *}$ & 0.005 & 0.026 & 0.020 \\
\hline Gentrify \& Score 580-649 & 0.007 & 0.005 & $0.058^{* * *}$ & 0.021 \\
\hline Gentrify \& Score $<580$ & $-0.010^{* *}$ & 0.004 & $0.082^{* * *}$ & 0.020 \\
\hline Gentrify + Gentrify \& Score $<580$ & $-0.007^{* * *}$ & & $0.024^{* *}$ & \\
\hline
\end{tabular}

Note: From linear probability regressions using pooled data (2003-2004 and 2006-2014);

$* * *, * *, *$

represent significant at $0.01,0.05$, or 0.1 level, respectively; control variables include risk score, household size, age, mortgage status, serious delinquency, distance to City Hall and universities, year dummies, and neighborhood indicators; estimation is based on data from the FRBNY Consumer Credit Panel/Equifax. 
Table 5

Estimating the Effect of Gentrification Types on Residential Mobility for Low- Score Residents (Individuals without Mortgages Only)

\begin{tabular}{|c|c|c|c|c|}
\hline & \multicolumn{2}{|c|}{ Move (Any Move) as the Outcome } & \multicolumn{2}{|c|}{ Move Downward as the Outcome (Movers) } \\
\hline & Coefficient & Standard Error & Coefficient & Standard Error \\
\hline \multicolumn{5}{|c|}{ Gentrification type \& low score (Ref: Nongentrify \& Score 580+) } \\
\hline Low score $(<580)$ & $-0.007^{* * *}$ & 0.002 & $0.053^{* * *}$ & 0.007 \\
\hline Continued gentrification & $0.029^{* * *}$ & 0.003 & $-0.054^{* * * *}$ & 0.012 \\
\hline Weak gentrification & $-0.009^{* *}$ & 0.005 & 0.016 & 0.021 \\
\hline Moderate gentrification & -0.004 & 0.003 & 0.008 & 0.013 \\
\hline Intense gentrification & $0.045^{* * *}$ & 0.004 & $-0.048^{* * * *}$ & 0.015 \\
\hline Continued gentrification \& low score & $-0.022^{* * *}$ & 0.004 & $0.102^{* * * *}$ & 0.016 \\
\hline Weak gentrification \& low score & -0.005 & 0.007 & $-0.053^{*}$ & 0.032 \\
\hline Moderate gentrification \& low score & -0.001 & 0.005 & 0.021 & 0.020 \\
\hline Intense gentrification \& low score & $-0.036^{* * *}$ & 0.008 & $0.092^{* * * *}$ & 0.025 \\
\hline Other controls & yes & & yes & \\
\hline \multicolumn{5}{|l|}{ Sum of coefficients } \\
\hline Continued + Continued \& low score & $0.008^{*}$ & & $0.048^{* * *}$ & \\
\hline Weak + Weak \& low score & $-0.014^{* *}$ & & -0.037 & \\
\hline Moderate + Moderate \& low score & -0.005 & & $0.029^{*}$ & \\
\hline Intense + Intense \& low score & 0.009 & & $0.044^{*}$ & \\
\hline R Square & 0.043 & & 0.081 & \\
\hline Number of observations & 209,989 & & 20,120 & \\
\hline
\end{tabular}

Note: From linear probability regressions using pooled data (2003-2004 and 2006-2014);

****, **,

represent significant at $0.01,0.05$, or 0.1 level, respectively; control variables include risk score, household size, age, mortgage status, serious delinquency, distance to City Hall and universities, year dummies, and neighborhood indicators; estimation is based on data from the FRBNY Consumer Credit Panel/Equifax. 


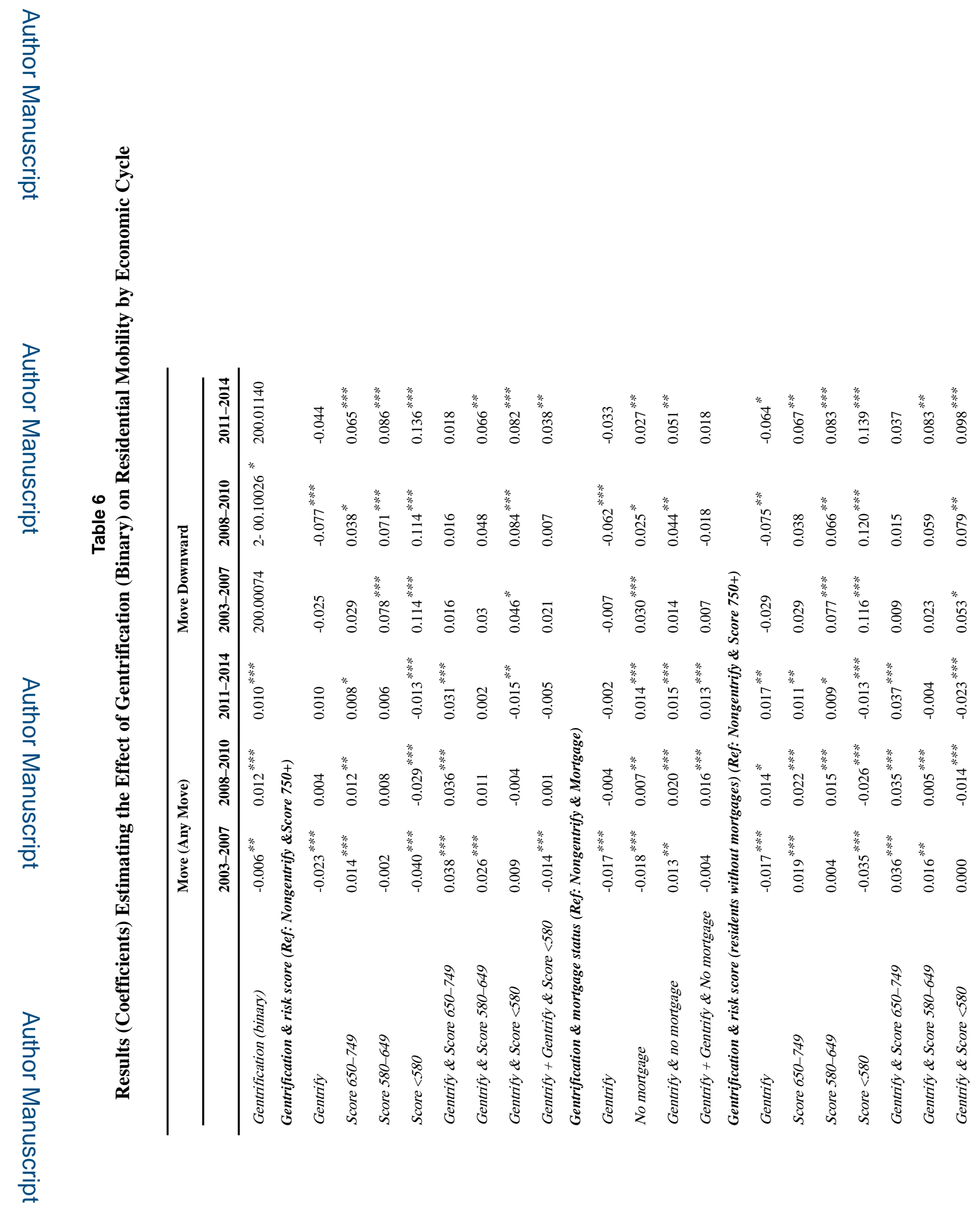

Reg Sci Urban Econ. Author manuscript; available in PMC 2017 November 01. 
Ding et al.

Page 33

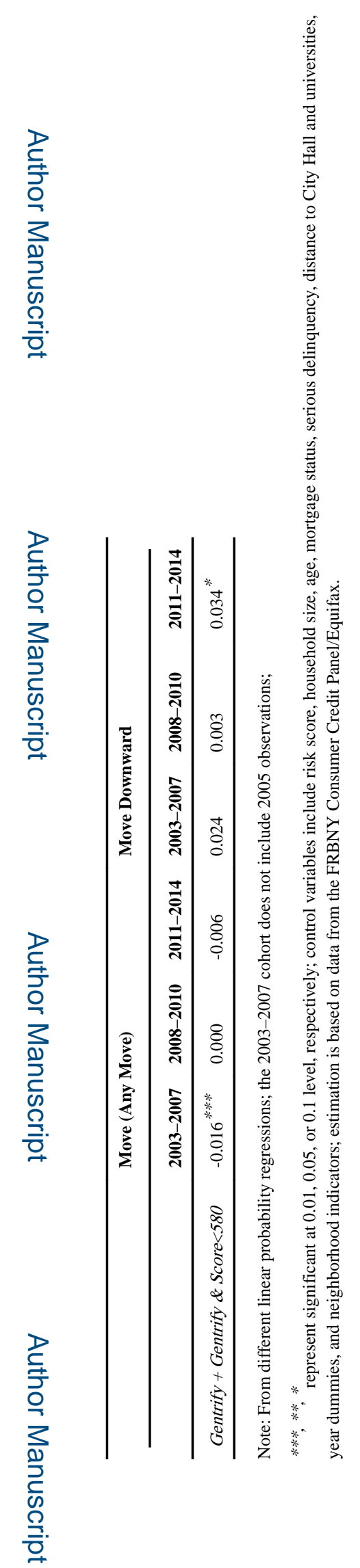

Reg Sci Urban Econ. Author manuscript; available in PMC 2017 November 01. 


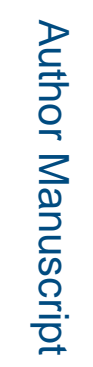

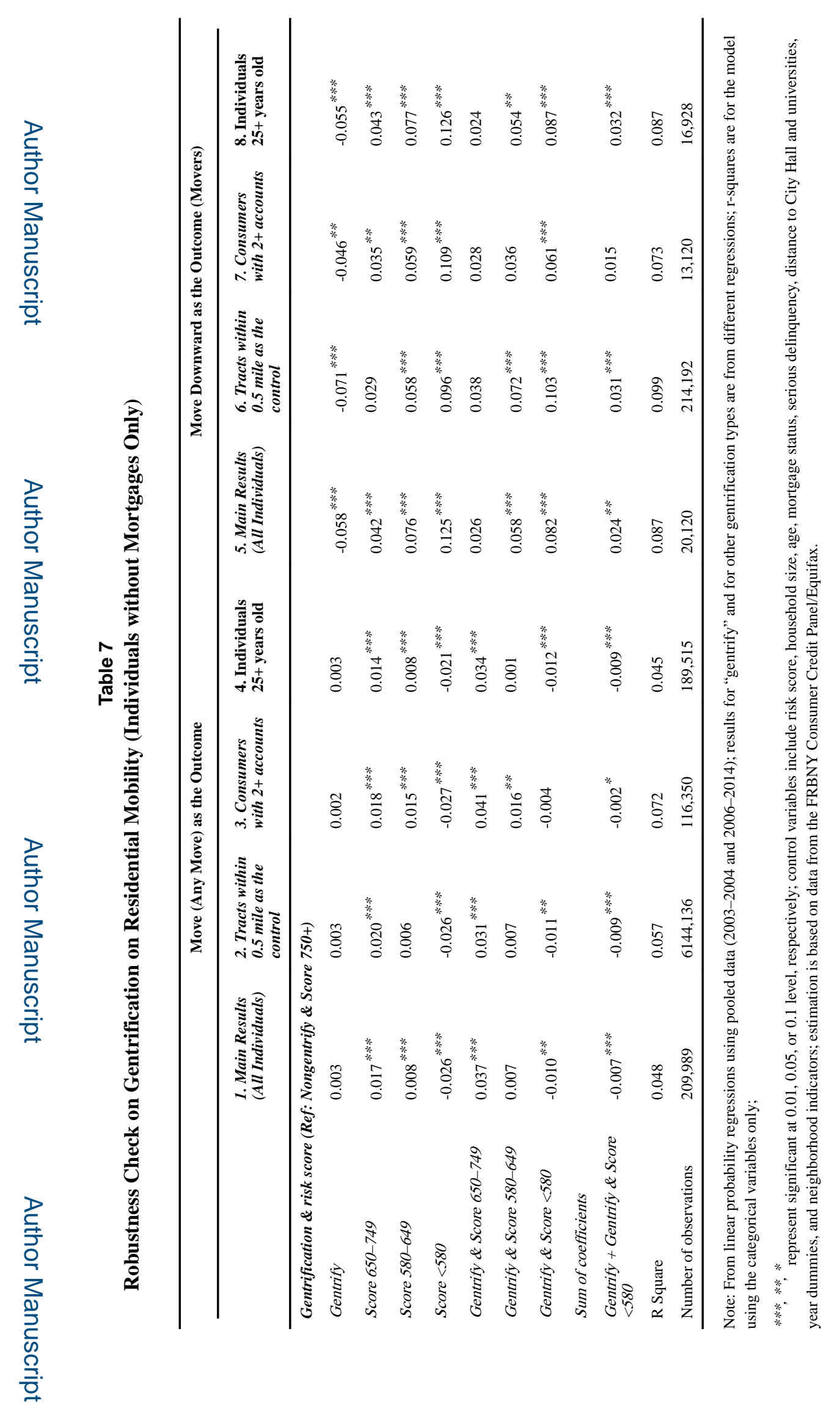

Reg Sci Urban Econ. Author manuscript; available in PMC 2017 November 01. 